\title{
Guidelines for Optimizing Outcomes with Immediate Molar Implant Placement
}

Ketabi $\mathbf{M}^{1}$ and Deporter $\mathrm{D}^{2 *}$

${ }^{1}$ Department of Periodontology, Islamic Azad University,

Iran

${ }^{2}$ Department of Periodontology, Oral Reconstructive Center, University of Toronto, Canada

*Corresponding author: Douglas Deporter, Department of Periodontology, Oral Reconstructive Center, University of Toronto, 124 Edward Street, Toronto, Ontario, Canada

Received: March 21, 2017; Accepted: May 08, 2017; Published: May 24, 2017

\begin{abstract}
This paper is a follow-up to a recent systematic literature review with metaanalysis of outcomes when using immediate molar implants (IMIs). An attempt has been made to offer guidelines to assist clinicians in their successful use of this treatment approach. The surgeon's ability, proper case selection, socket anatomy, and specific modifications in osteotomy preparation all are crucial in avoiding errors, complications and implant failure. While long-term data are sparse, IMIS appear to be a viable treatment option if the offered guidelines are strictly followed.
\end{abstract}

Keywords: Tooth extraction; Dental implantation; Endosseous; Guided tissue regeneration

\section{Introduction}

We have recently published a systematic review and metaanalysis of literature published from November 2008 to May 2015 reporting outcomes following immediate molar dental implant (IMI) placement [1]. The search format was that recommended by the Academy of Osseointegration Workshop on the State of Science on Implant Dentistry (SSID) [2,3]. The search language used was similar to that employed in a previous review conducted by others on IMI data up to October 2008 [4]. Criteria for qualification of studies to be included in the analysis were: i) at least $10 \mathrm{IMIs}$; ii) minimum followup 1 year in function; iii) clearly reported/interpretable survival and/or success (based on crestal bone loss) data; and iv) use of rootform, solid, titanium or titanium alloy implants. Fifteen publications fulfilling these criteria were identified, none of which were doubleblind, randomized, controlled prospective clinical trials. Recognizing this limitation, our analysis supported Atieh's earlier conclusion [4] that it is possible to obtain good outcomes with IMIs with the added proviso that those of diameters $>6 \mathrm{~mm}$ may be at greater risk of failure.

There are obvious advantages for patients and clinicians in providing immediate implant replacement of molar teeth. These include fewer and potentially less invasive surgical procedures, greater patient acceptance, less chair time, lower treatment fees, shorter treatment times, and potentially fewer risks. The clinician needs to be aware, however, that achieving success with IMIs is affected by many factors. In the present paper, we have attempted to formulate guidelines for the successful use of IMIs. Considerations will include case selection, reason for extraction, quality and quantity of keratinized tissue, socket anatomy and how it impacts osteotomy preparation, implant design, and initial implant stability.

\section{Discussion}

\section{Case selection}

As with all technique-sensitive surgical procedures, not all clinicians will be capable of successfully employing IMI procedures because of infrequent usage of the procedure, failure to follow strict protocols, inadequately trained support staff and/or inability to manage the associated stress [5]. Likewise, not all molar sockets will be appropriate for IMI placement thereby making careful case selection crucial. Patients should be non-smokers since smokers have been shown to have 10x the risk of IMI failure as non-smokers [6]. Other patient contraindications include history of head and neck radiation in the previous 12 to 24 months [7], uncontrolled diabetes [8], use of anti-resorptive [9] or RANK ligand-inhibiting [10] drugs, and parafunctional habits such as bruxism [11].

In most situations, a pre-operative CBCT scan should be done to allow pre-treatment assessment of buccal bone thickness and proximity of vital structures [12]. In posterior mandible, Froum, et al. [13] suggested that safe placement of an $I M I$ is likely if the distance from root apices to the nerve canal is at least $6 \mathrm{~mm}$ as measured on $\mathrm{CBCT}$, accepting that up to $4 \mathrm{~mm}$ of apical bone must be engaged to ensure sufficient initial IMI stability to avoid micro-movements [14]. Lin, et al. [15] used CBCT cross-sectional views and virtual IMI placements to predict the risk of nerve damage with mandibular IMIs. In a sample of 237 subjects, the mean distances between molar root apices and nerve canal $(R A C)$ were $7.0 \pm 2.9 \mathrm{~mm}$ for first molar and $4.3 \pm 2.7 \mathrm{~mm}$ for second molar sites. Nerve damage was likely to occur in $69.9 \%$ of second molar sites, but the risk was reduced to $35.4 \%$ at first molar sites. The probability of nerve damage decreased by $26 \%$ with every $1 \mathrm{~mm}$ increase in RAC. The investigators also found that $57.5 \%$ of first molars and $62.3 \%$ of second molars had lingual mandibular ridge concavities adding the risk of lingual plate perforation and arterial damage. In another computer-based simulation study of IMI placement in posterior mandible [16] the same investigators predicted that the risk of lingual plate perforation decreased by $34 \%$ for every $1 \mathrm{~mm}$ increase in RAC. Given all of this information, a reasonable guideline to follow is the $6 \mathrm{~mm}$ minimum $R A C$ rule of Froum. With an RAC less than $6 \mathrm{~mm}$, it becomes safer to undertake socket preservation grafting with delayed implant placement, and clearly this is more likely to be the case for mandibular second molars.

$I M I$ sites with a thick buccal gingival biotype (i.e., a periodontal probe cannot be seen through the tissue when inserted into the 


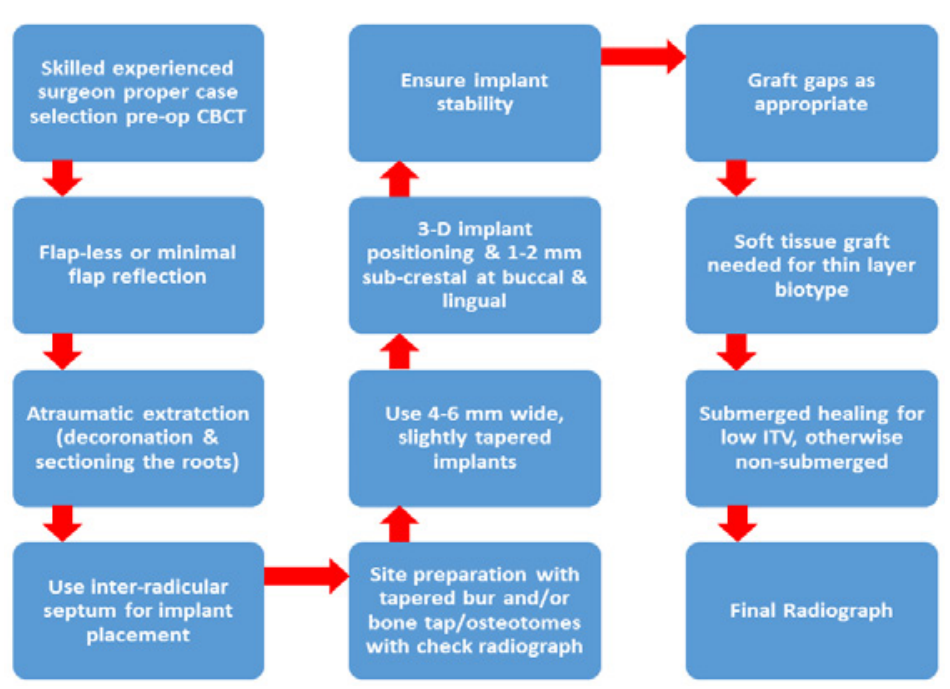

Flow Chart:

gingival sulcus) and a keratinized gingiva vertical width of $\geq 2 \mathrm{~mm}$ are preferred since thin and/or narrow keratinized tissue will predispose to crestal bone resorption and peri-implant gingival recession [1720]. Should textured implant surfaces become exposed as a result of crestal bone loss, there is the risk of peri-implantitis and progressive bone loss [21]. As well, once restored, implants with thin, narrow keratinized tissue are more likely to be associated with bleeding on probing and brushing discomfort [22]. If adequate keratinized gingiva is lacking, a graft of palatal connective tissue can be harvested and inserted under the buccal and lingual/palatal flap margins and over the implant as one would place a membrane [23]. Alternatively, a dense PTFE membrane can be placed in a similar fashion over the implant and left exposed so as to promote healing by secondary intention with generation of new keratinized tissue [24].

The majority of recent IMI clinical investigations did not include molars lost to chronic severe periodontitis (or aggressive periodontitis) or to apical pathology [1], the consensus being that IMI placement should be for molars lost to non-restorable caries, root fracture or endodontic treatment complications. While there is some evidence that periapical infection and associated bone defects may not be an absolute contraindication for immediate implantation provided that thorough debridement and antibiotic coverage are employed $[25,26]$ further data from randomized controlled clinical trials are required to confirm this procedure to be safe and to establish an appropriate protocol [27].

\section{Extraction technique}

The majority of investigators [1] who have undertaken studies of IMIs have used antibiotics (most commonly amoxicillin or clindamycin in the case of penicillin allergy) starting before or immediately after the procedure. They stressed the importance of atraumatic tooth removal, ideally with flap-less surgery to minimize disturbance of the buccal plate's periosteal blood supply [28], crestal bone loss [29] and buccal soft tissue recession [30].

Prior to extraction, molars are generally modified by coronectomy and sectioned so as to allow removal of each root separately using periotomes and/or piezo surgery tips [31,32]. Bucco-lingual movements of the roots should be minimized in order to avoid buccal plate damage. Alternatively, after de-coronation, the tooth may be left in situ while the osteotomy is created through the tooth's furcation area, the roots being removed only after osteotomy completion and just prior to implant insertion [33,34]. If the roots are removed first, the surgeon should use a surgical stent to ensure correct implant positioning, while still being aware of socket anatomy particularly buccal bone thickness and crestal height. Following IMI insertion, some investigators have stressed that wound closure and submerged healing are important in minimizing the risk of infection and achieving osseointegration, while others made no attempt to cover the implant site relying only on soft tissue adaptation with or without gap grafting to promote site healing and avoiding later re-entry [1]. Clearly with the non-submerged approach the quantity and quality of keratinized gingival tissue will be a factor requiring consideration. Even with submerged IMI placement, there can be a risk of infection if dehiscence of the overlying soft tissues occurs during site healing [6]. Most investigators do not, however, include the incidence of periimplantitis causing $I M I$ failure whether that is early or late [35].

\section{Managing socket anatomy}

Socket walls: Socket anatomy is central to successful IMI outcomes. Firstly, as already stated, intact socket walls are essential in order to avoid the concomitant need and challenges/complications of simultaneous guided bone augmentation grafting. Where one or more socket walls are missing or have a significant dehiscence, socket preservation grafting $[24,36]$ and delayed implant placement are more appropriate. Since placing IMIs does not eliminate post-extraction alveolar ridge remodeling $[37,38]$, it is recommended that IMIs be submerged by up to $2 \mathrm{~mm}$ on the buccal aspect to compensate for the expected buccal crestal bone loss $[29,33,39]$. This is particularly important if the thickness of the buccal wall is $<2 \mathrm{~mm}[40,41]$. Huang, et al. [42] compared implants placed at the level of the bone crest to those submerged by $1.5 \mathrm{~mm}$ in dogs, and found the latter to have better crestal bone preservation in relation to the implant neck after 4 months in function. Submerging the implant may also increase bone- 
Table 1: Surgical management for immediate molar implantation based on socket (IRS) classification of smith \& tarnow.

\begin{tabular}{|c|c|c|c|c|}
\hline $\begin{array}{l}\text { Type of } \\
\text { IRS }\end{array}$ & Condition of Buccal Wall & Gingival Biotype & Surgical protocol & Healing Phase \\
\hline$A$ or $B$ & intact \&thick ( $\geq 2 \mathrm{~mm}$ ) & thick \& wide $(\geq 2 \mathrm{~mm})$ & flap-less + gap grafting as needed & $\begin{array}{l}\text { 1-stage if ITV35 to } 50 \mathrm{Ncm} \\
\text { or RFA }>60\end{array}$ \\
\hline$A$ or $B$ & intact \&thick ( $\geq 2 \mathrm{~mm}$ ) & thin \& narrow $(<2 \mathrm{~mm})$ & flap + gap grafting as needed + CT graft or d-PTFE barrier & 2-stage \\
\hline $\mathrm{A}$ or $\mathrm{B}$ & Intact \&thin $(<2 \mathrm{~mm})$ & thick \& wide $(\geq 2 \mathrm{~mm})$ & $\begin{array}{c}\text { flap +subcrestal placement \&lingual implant positioning to } \\
\text { create buccal gap for grafting }\end{array}$ & 1-stage or 2-stage \\
\hline $\mathrm{A}$ or $\mathrm{B}$ & Intact \&thin $(<2 \mathrm{~mm})$ & thin \& narrow $(<2 \mathrm{~mm})$ & $\begin{array}{c}\text { flap + subcrestal placement + lingual positioning to create buccal } \\
\text { gap for grafting + CT graft or d-PTFE barrier, or } \\
\text { socket preservation \& delayed implant placement }\end{array}$ & 2-stage \\
\hline Type C & Intact \&thick ( $\geq 2 \mathrm{~mm}$ ) & thick \& wide $(\geq 2 \mathrm{~mm})$ & flap-less +IRS removal + wider implant \&gap grafting as needed & $\begin{array}{c}\text { 1-stage if ITV } 35-50 \mathrm{Ncm} \\
\text { or RFA }>60\end{array}$ \\
\hline Type C & intact \&thick ( $\geq 2 \mathrm{~mm}$ ) & thin \& narrow $(<2 \mathrm{~mm})$ & $\begin{array}{c}\text { flap + IRS removal + wider implant + gap grafting as needed + } \\
\text { CT graft or d-PTFE barrier or } \\
\text { socket preservation \& delayed implant placement }\end{array}$ & 2-stage \\
\hline Type C & Intact \&thin $(<2 \mathrm{~mm})$ & thick \& wide $(\geq 2 \mathrm{~mm})$ & $\begin{array}{c}\text { flap + IRS removal + wider implant with subcrestal placement+ } \\
\text { xenograft buccal over-grafting \& gap grafting as needed +CT } \\
\text { graft or d-PTFE barrier or } \\
\text { socket preservation \& delayed implant placement }\end{array}$ & 2-stage \\
\hline Type C & Intact \& thin $(<2 \mathrm{~mm})$ & Thin \& narrow $(<2 \mathrm{~mm})$ & socket preservation \& delayed implant placement & 2-stage \\
\hline $\begin{array}{l}\text { Type A,B } \\
\text { or C }\end{array}$ & Lack of Buccal wall & & socket preservation \& delayed implant placement & \\
\hline
\end{tabular}

to-implant contact (i.e., osseointegration) [43]. If the implant cannot be adequately submerged in sites with a thin buccal plate because of vital structure proximity, consideration can be given to placing it towards the lingual/palatal to avoid contact with the buccal bone [44]. This will leave a gap that can be grafted with a slowly resorbable material such as xenograft or mineralized allograft with or without a barrier membrane which will minimize buccal bone resorption [45]. Generally, gaps between the coronal part of the implant and any socket wall are similarly grafted if their widths are $\geq 2 \mathrm{~mm}[14,46$ 49]. Buccal over-grafting (i.e., on the outer periosteal buccal bone surface in a pouch under the flap) with xenograft can be of benefit in situations where the implant surface-to-buccal bone distance $\geq 4 \mathrm{~mm}$ as this too will reduce loss in bucco-lingual/palatal ridge width and preserve/improve anatomical contours [50].

Inter-radicular septum: Inter-radicular septal/furcal bone (IRB) is another anatomic challenge with IMI placement. Under ideal circumstances, the buccal and lingual/palatal aspects of the IRB should be maintained and used as initial implant-stabilizing buttresses. Smith and Tarnow [51] classified molar sockets into three types based on the amount of $I R B$ remaining. Managing $I R B$ will present varying levels of difficulty and vary depending on the IRB type, the thickness of buccal bone and the quantity of keratinized gingiva (Table 1). Type $A$ sockets are designated as those with sufficient IRB bulk to contain the osteotomy in its entirety. With this socket type, the authors [51] recommended that an implant should be fully seated apico-coronally in $I R B$, and that being the case, any remaining root socket defects/ gaps need not necessarily be grafted. This would, however, assume that they can be covered by repositioned thick keratinized gingival tissue that is adequately supported by remaining alveolus. If not, gap grafting covered with a connective tissue graft or a barrier is advisable (Table 1).

Type $B$ sockets were defined as those having sufficient IRB to stabilize the implant, but not completely house it [51]. Management will depend on the buccal bone thickness and the quality/quantity of keratinized tissue (Table 1). If the buccal bone is thin $(<2 \mathrm{~mm})$, the implant can be submerged up to $2 \mathrm{~mm}$ below the buccal crest. Some clinicians have proposed removing all or part of the IRB in Type $B$ sockets, for example using round burs [52], trephines [53] or piezo surgical tips before initiating osteotomy preparation with a pilot bur. In contrast, Fugazzotto [54] suggested that this IRB can be left and managed with a modified drilling protocol. Specifically, the first bur was started at an angle near the base of the IRB. Once a stable entry point was established, the bur was then slowly up-righted as osteotomy preparation continued. Thereafter, each bur in sequence entered the site at a slightly less acute angle before being straightened up, so that in the end, the preparation allowed implant placement in the correct position stabilized by the IRB buccal and lingual bone buttresses. To avoid final implant positioning being too far buccal in posterior mandible because of bur drift buccally, Hayacibara, et al. [55]. Initiated drilling into the IRB towards the lingual. Finally, some clinicians have favored managing Type $B$ sockets by placing an IMI into one or other of a mandibular molar root sockets or into the palatal root socket of maxillary molars [56], but this is the least favorable approach as it results in poor restoration emergence profiles and compromised homecare.

Type $C$ sockets of Smith and Tarnow [51] are those with insufficient septal bone to stabilize the implant without engaging socket walls for support. With this last socket type, the IRB will generally be removed and an implant of sufficient diameter placed so as to make maximal contact with available socket walls while still respecting the buccal bone thickness. If this results in a thin buccal plate remaining, buccal over-grafting with xenograft can be added to the protocol. With socket Types $B$ and $C$ in mandible, in order to achieve maximum initial stability, it was stressed that the $I M I$ apex should engage $\geq 4 \mathrm{~mm}$ of native bone.

In the case of maxillary IMIs, there may be limited bone between the socket apex and the maxillary sinus. In such sites, in order to develop sufficient bone to house the implant, osteotomy preparation can include localized indirect, sinus floor elevation using osteotomes [56-60], specialized burs [61] or piezoelectric tips [62]. Particulate mineralized allograft or xenograft particles or autogenous PRP-fibrin clots [63] often are used in these procedures to maximize new bone formation around the implant apex. Alternatively, if the IRB was wide mesio-distally, Fugazzotto used a small diameter trephine to 
free a plug of $I R B$ bone, and subsequently condensed it apically as an autogenous graft using osteotomes, elevating the sinus membrane and providing a tented space in the sinus to receive the implant apex $[59,64]$. In some sites with limited subantral bone, sinus elevation grafting can be avoided or minimized by using a short, ultra-wide ( $>6 \mathrm{~mm}$ ) implant $[39,65]$. However, if the buccal bone is thin and the implant platform is not submerged $2 \mathrm{~mm}$ below the crest as recommended by the manufacturer, unwanted crestal resorption may be the result.

\section{Implant design}

Investigators have used cylindrical and tapered implant designs both with moderately rough surface textures (e.g. particle-blasted, acid-treated) as IMIs [1]. There may be some advantage with tapered designs in improving initial implant stability especially in bone of low density [66]. However, excessive taper may lead to increased early failure of wide diameter implants used as IMIs in mandible possibly due to the excessive torque needed to install them causing unfavorable compression of crestal bone with its resorption [52]. Atieh and Shahmiri [67] studied the effect of various degrees of implant taper on crestal bone of mandibular molar implants using a finite element analysis model, and concluded that small taper angles (e.g. 2 to $5^{\circ}$ ) placed less stress on crestal bone than larger ones (up to $14^{\circ}$ ) after the onset of implant function. While a variety of different IMI implant thread configurations have been used, as yet none has proved to be superior (Chart 1).

Implant diameter also appears to be a factor in the survival of IMIs assuming appropriate surgical technique and adequate initial implant stability. Finite element analyses by Ormianer, et al. [68] suggested that a $6 \mathrm{~mm}$ diameter $I M I$ reduced crestal bone stresses compared to those with 3.7 or $4.7 \mathrm{~mm}$ diameters provided there was a minimum of $1.8 \mathrm{~mm}$ buccal bone thickness. Appropriately, most investigators have used IMI diameters $>4.5 \mathrm{~mm}$ [1] which if need be can allow them to be used in shorter lengths [69]. Jiansheng, et al. [19] investigated the use of short (5.7 to $8 \mathrm{~mm}$ ), wide (5 to $7 \mathrm{~mm}$ ) implants as IMIs. A minimum keratinized tissue width of $2 \mathrm{~mm}$ was required and implants were submerged about $3 \mathrm{~mm}$ below the bone crest. After a mean of 2 years in function, the survival was $99.4 \%$. However, technical difficulties/complications can arise with ultrawide implants $(>6 \mathrm{~mm}$ ) especially in posterior mandible where the necessarily wide diameter burs can stall and become locked in place due to excessive friction. It also may be difficult or impossible to seat these implants $2 \mathrm{~mm}$ below the alveolar crest as recommended [52], compromising the final buccal bone thickness. In this case, thought should be given to using a smaller diameter implant (e.g. $5 \mathrm{~mm}$ ) and placing it slightly to the lingual [70], keeping in mind that smaller diameter implants placed as IMIs will need to be submerged to a level in bone that will allow development of an esthetically-pleasing and hygienic emergence profile ("running room") [51]. Alternatively, a $4.8 \mathrm{~mm}$ diameter implant with a coronal shoulder diameter of 6.5 $\mathrm{mm}$ has been used $[54,64]$.

\section{Initial IMI stability}

As with delayed implant placement, IMIs must have good initial stability to integrate. Traditionally, high insertion torque (ITV) has been considered the best indication of good implant stability. ITVs of 35 to $50 \mathrm{Ncm}$ appear to be appropriate based on the author's (MK) experience. However, if torqueing force is excessive, despite there being good initial implant stability (i.e., avoidance of early micro-movements), there may be strain-related micro-fractures and compression necrosis in the peri-implant cortical bone [71]. Before new cortical bone can be formed around implants placed in this fashion, a resorptive phase is needed to remove the damaged bone. This will be accompanied by a temporary reduction in implant stability which could result in micro-movements sufficient to inhibit osteogenesis and early implant failures. This has led to the suggestion that a lesser torque (e.g. $25 \mathrm{Ncm}$ ) may be preferable, and that adequate implant stability is better verified with resonance frequency testing (i.e., axial stability) than by achieving high initial torque values (rotational stability) [72]. A resonance frequency value (RFV) of $\geq 60$ is generally considered to be sufficient for implant integration [73].

\section{Conclusions \& Suggested Guidelines}

1. Based on published literature, the use of immediate molar implants appears to be a valid treatment in the hands of skilled clinicians, although long-term performance data are limited. Given the difficulty of the procedure clinicians should follow strict guidelines to minimize the risk of complications/failures. Based on current literature, the following IMI placement guidelines are recommended:non-smokers only

2. a pre-op CBCT scan to minimize risk especially in mandible

3. thick gingival biotype and adequate keratinized tissue width ( $\geq 2 \mathrm{~mm})$

4. atraumatic extraction with flap-less surgery if feasible

5. only sites with intact socket walls after extraction

6. osteotomy preparation will vary with socket type (Table 1)

7. IMIs to be submerged (up to $2 \mathrm{~mm}$ ) below the buccal bone crest if crestal buccal bone is thin $(<2 \mathrm{~mm})$

8. thin buccal plate $(<2 \mathrm{~mm})$ may require more lingual placement of the implant with gap grafting and/or buccal overgrafting

9. gaps between implant and socket walls generally grafted if $\geq 2 \mathrm{~mm}$ in width

10. xenograft or mineralized allograft preferred

11. initial implant stability verified

12. Submerged healing if ITV $<25$ and/or RFV $<60$.

\section{References}

1. Ketabi M, Deporter D, Atenafu EG. A Systematic Review of Outcomes Following Immediate Molar Implant Placement Based on Recently Published Studies. Clin Implant Dent Relat Res. 2016; 18: 1084-1094.

2. Iacono VJ, Cochran DL. State of the science on implant dentistry: a workshop developed using an evidence-based approach. Int J Oral Maxillofac Implants. 2007; 22: 7-10.

3. Proskin HM, Jeffcoat RL, Catlin A, Campbell J, Jeffcoat MK. A meta-analytic approach to determine the state of the science on implant dentistry. Int J Oral Maxillofac Implants. 2007; 22: 11-18.

4. Atieh MA, Payne AG, Duncan WJ, de Silva RK, Cullinan MP. Immediate placement or immediate restoration/loading of single implants for molar tooth replacement: a systematic review and meta-analysis. Int J Oral Maxillofac Implants. 2010; 25: 401-415. 
5. Jemt T, Olsson M, Renouard F, Stenport V, Friberg B. Early Implant Failures Related to Individual Surgeons: An Analysis Covering 11,074 Operations Performed during 28 Years. Clin Implant Dent Relat Res. 2016; 18: 861-872.

6. Urban T, Kostopoulos L, Wenzel A. Immediate implant placement in molar regions: risk factors for early failure. Clin Oral Implants Res. 2012; 23: 220 227 .

7. Claudy MP, Miguens SA, Jr., Celeste RK, Camara Parente R, Hernandez PA da Silva AN Jr. Time interval after radiotherapy and dental implant failure: systematic review of observational studies and meta-analysis. Clin Implant Dent Relat Res. 2015; 17: 402-411.

8. Naujokat H1, Kunzendorf B2, Wiltfang J2. Dental implants and diabetes mellitus-a systematic review. Int J Implant Dent. 2016; 2: 5.

9. Marx RE. A decade of bisphosphonate bone complications: what it has taugh us about bone physiology. Int J Oral Maxillofac Implants. 2014; 29: e247-258.

10. Aragon-Ching JB, Ning YM, Chen CC, Latham L, Jean-Pierre G, Gulley GL, et al. Higher incidence of Osteonecrosis of the Jaw (ONJ) in patients with metastatic castration resistant prostate cancer treated with anti-angiogenic agents. Cancer Invest. 2009; 27: 221-226.

11. Chrcanovic BR, Kisch J, Albrektsson T, Wennerberg A. Bruxism and dental implant failures: a multilevel mixed effects parametric survival analysis approach. J Oral Rehabil. 2016; 43: 813-823.

12. Benavides E, Rios HF, Ganz SD, An CH, Resnik R, Reardon GT, et al. Use of cone beam computed tomography in implant dentistry: the International Congress of Oral Implantologists consensus report. Implant Dent. 2012; 21: 78-86.

13. Froum S, Casanova L, Byrne S, Cho SC. Risk assessment before extraction for immediate implant placement in the posterior mandible: a computerized tomographic scan study. J Periodontol. 2011; 82: 395-402.

14. Koh RU, Rudek I, Wang HL. Immediate implant placement: positives and negatives. Implant Dent. 2010; 19: 98-108.

15. Lin MH, Mau LP, Cochran DL, Shieh YS, Huang PH, Huang RY. Risk assessment of inferior alveolar nerve injury for immediate implant placement in the posterior mandible: a virtual implant placement study. J Dent. 2014 42: $263-270$.

16. Huang RY, Cochran DL, Cheng WC, Lin MH, Fan WH, Sung CE, et al. Risk of lingual plate perforation for virtual immediate implant placement in the posterior mandible: A computer simulation study. J Am Dent Assoc. 2015; 146: 735-742.

17. Bouri A, Bissada N, Al-Zahrani MS, Faddoul F, Nouneh I. Width of keratinized gingiva and the health status of the supporting tissues around dental implants. Int J Oral Maxillofac Implants. 2008; 23: 323-326

18. Linkevicius T, Apse P, Grybauskas S, Puisys A. The influence of soft tissue thickness on crestal bone changes around implants: a 1-year prospective controlled clinical trial. Int J Oral Maxillofac Implants. 2009; 24: 712-719.

19. Jiansheng H, Dongying X, Xianfeng W, Baoyi X, Qiong L, Jincai Z. Clinica evaluation of short and wide-diameter implants immediately placed into extraction sockets of posterior areas: a 2-year retrospective study. J Oral Implantol. 2012; 38: 729-737.

20. Bengazi F, Botticelli D, Favero V, Perini A, Urbizo Velez J, Lang NP. Influence of presence or absence of keratinized mucosa on the alveolar bony crest level as it relates to different buccal marginal bone thicknesses. An experimental study in dogs. Clin Oral Implants Res. 2014; 25: 1065-1071.

21. Berglundh T, Gotfredsen K, Zitzmann NU, Lang NP, Lindhe J. Spontaneous progression of ligature induced peri-implantitis at implants with different surface roughness: an experimental study in dogs. Clin Oral Implants Res. 2007; 18: 655-661.

22. Souza AB, Tormena M, Matarazzo F, Araújo MG. The influence of periimplant keratinized mucosa on brushing discomfort and peri-implant tissue health. Clin Oral Implants Res. 2016; 27: 650-655.

23. Bianchi AE, Sanfilippo F. Single-tooth replacement by immediate implant and connective tissue graft: a 1-9-year clinical evaluation. Clin Oral Implants Res. 2004; 15: 269-277.
24. Barber HD, Lignelli J, Smith BM, Bartee BK. Using a dense PTFE membrane without primary closure to achieve bone and tissue regeneration. $\mathrm{J}$ Oral Maxillofac Surg. 2007; 65: 748-752.

25. Fugazzotto P. A retrospective analysis of immediately placed implants in 418 sites exhibiting periapical pathology: results and clinical considerations. Int J Oral Maxillofac Implants. 2012; 27: 194-202.

26. Jofre J, Valenzuela D, Quintana P, Asenjo-Lobos Co. Protocol for immediate implant replacement of infected teeth. Implant Dent. 2012; 21: 287-294.

27. Chrcanovic BR, Martins MD, Wennerberg A. Immediate placement of implants into infected sites: a systematic review. Clin Implant Dent Relat Res. 2015; 1: e1-e16.

28. Berglundh T, Lindhe J, Jonsson K, Ericsson I. The topography of the vascular systems in the periodontal and peri-implant tissues in the dog. J Clin Periodontol. 1994; 21: 189-193.

29. Fickl S, Zuhr O, Wachtel H, Bolz W, Huerzeler M. Tissue alterations after tooth extraction with and without surgical trauma: a volumetric study in the beagle dog. J Clin Periodontol. 2008; 35: 356-363.

30. Blanco J, Alves CC, Nunez V, Aracil L, Muñoz F, Ramos I. Biological width following immediate implant placement in the dog: flap vs. flapless surgery. Clin Oral Implants Res. 2010; 21: 624-631.

31. Sharma SD, Vidya B, Alexander M, Deshmukh S. Periotome as an Aid to Atraumatic Extraction: A Comparative Double Blind Randomized Controlled Trial. J Maxillofac Oral Surg. 2015; 14: 611-615.

32. Blus C, Szmukler-Moncler S. Atraumatic tooth extraction and immediate implant placement with Piezosurgery: evaluation of 40 sites after at least 1 year of loading. Int J Periodontics Restorative Dent 2010; 30: 355-363.

33. Rodriguez-Tizcareno $\mathrm{MH}$, Bravo-Flores $\mathrm{C}$. Anatomically guided implant site preparation technique at molar sites. Implant Dent. 2009; 18: 393-401.

34. Rebele SF, Zuhr O, Hurzeler MB. Pre-extractive interradicular implant bed preparation: case presentations of a novel approach to immediate implant placement at multirooted molar sites. Int J Periodontics Restorative Dent. 2013; 33: 89-96.

35. Quirynen M, Van Assche N, Botticelli D, Berglundh T. How does the timing of implant placement to extraction affect outcome? Int J Oral Maxillofac Implants. 2007; 22: 203-223.

36. Tomlin EM, Nelson SJ, Rossmann JA. Ridge preservation for implant therapy: a review of the literature. Open Dent J. 2014; 8: 66-76.

37. Araújo MG, Sukekava F, Wennström JL, Lindhe J. Tissue modeling following implant placement in fresh extraction sockets. Clin Oral Implants Res. 2006; 17: 615-624.

38. Clementini M, Tiravia L, De Risi V, Vittorini Orgeas G, Mannocci A, de Sanctis M. Dimensional changes after immediate implant placement with or withou simultaneous regenerative procedures: a systematic review and metaanalysis. J Clin Periodontol. 2015; 42: 666-677.

39. Vandeweghe S, Ackermann A, Bronner J, Hattingh A, Tschakaloff A, De Bruyn $\mathrm{H}$. A retrospective, multicenter study on a novo wide-body implant for posterior regions. Clin Implant Dent Relat Res. 2012; 14: 281-292.

40. Spray JR, Black CG, Morris H, Ochi S. The influence of bone thickness on facial marginal bone response: Stage I placement through stage 2 uncovering Ann Periodontol. 2000; 5: 119-128.

41. Qahash M, Susin C, Polimeni G, Hall J, Wikesjö UM. Bone healing dynamics at buccal peri-implant sites. Clin Oral Implants Res. 2008; 19: 166-172.

42. Huang B, Meng H, Zhu W, Witek L, Tovar N, Coelho PG. Influence of placement depth on bone remodeling around tapered internal connection implants: a histologic study in dogs. Clin Oral Implants Res. 2015; 26: $942-$ 949.

43. Calvo-Guirado JL, Boquete-Castro A, Negri B, Delgado Ruiz R, GómezMoreno G, lezzi G. Crestal bone reactions to immediate implants placed at different levels in relation to crestal bone. A pilot study in Foxhound dogs. Clin Oral Implants Res. 2014; 25: 344-351. 
44. Tomasi C, Sanz M, Cecchinato D, Pjetursson B, Ferrus J, Lang NP, et al Bone dimensional variations at implants placed in fresh extraction sockets: a multilevel multivariate analysis. Clin Oral Implants Res. 2010; 21: 30-36.

45. Sanz M, Lindhe J, Alcaraz J, Sanz-Sanchez I, Cecchinato D. The effect of placing a bone replacement graft in the gap at immediately placed implants: a randomized clinical trial. Clin Oral Implants Res. 2016.

46. Wilson TG Jr, Schenk R, Buser D, Cochran D. Implants placed in immediate extraction sites: a report of histologic and histometric analyses of human biopsies. Int J Oral Maxillofac Implants. 1998; 13: 333-341.

47. Araújo MG1, Linder E, Lindhe J. Bio-Oss collagen in the buccal gap at immediate implants: a 6-month study in the dog. Clin Oral Implants Res. $2011 ; 22: 1-8$.

48. Cafiero C, Annibali S, Gherlone E, Grassi FR, Gualini F, Magliano A, et al. Immediate transmucosal implant placement in molar extraction sites: a 12-month prospective multicenter cohort study. Clin Oral Implants Res. 2008 19: $476-482$

49. Tallarico M, Xhanari E, Pisano M, De Riu G, Tullio A, Meloni SM. Single post-extractive ultra-wide $7 \mathrm{~mm}$-diameter implants versus implants placed in molar healed sites after socket preservation for molar replacement: 6-month post-loading results from a randomised controlled trial. Eur J Oral Implantol. 2016; 9: 263-275.

50. Capelli M, Testori T, Galli F, Zuffetti F, Motroni A, Weinstein R, et al. Implantbuccal plate distance as diagnostic parameter: a prospective cohort study on implant placement in fresh extraction sockets. J Periodontol. 2013; 84: 1768-1774.

51. Smith RB, Tarnow DP. Classification of molar extraction sites for immediate dental implant placement: technical note. Int J Oral Maxillofac Implants. 2013 28: $911-916$

52. Atieh MA, Alsabeeha NHM, Duncan WJ, K. de Silva R, P. Cullinan M, Schwass D, et al. Immediate single implant restorations in mandibular molar extraction sockets: a controlled clinical trial. Clin Oral Implants Res. 2013; 24: 484-496.

53. Prosper L, Crespi R, Valenti E, Capparé P, Gherlone E. Five-year follow up of wide-diameter implants placed in fresh molar extraction sockets in the mandible: immediate versus delayed loading. Int J Oral Maxillofac Implants. 2010; 25: 607-612.

54. Fugazzotto PA. Implant placement at the time of mandibular molar extraction: description of technique and preliminary results of 341 cases. J Periodontol. 2008; 79: 737-747

55. Hayacibara RM, Goncalves CS, Garcez J, Magro-Filho O, Esper H, Hayacibara MF. The success rate of immediate implant placement of mandibular molars: a clinical and radiographic retrospective evaluation between 2 and 8 years. Clin Oral Implants Res. 2013; 24: 806-811.

56. Penarrocha-Oltra D, Demarchi CL, Maestre-Ferrin L, Peñarrocha-Diago M, Peñarrocha-Diago M. Comparison of immediate and delayed implants in the maxillary molar region: a retrospective study of 123 implants. Int $\mathrm{J}$ Oral Maxillofac Implants. 2012; 27: 604-610.

57. Acocella A, Bertolai R, Sacco R. Modified insertion technique for immediate implant placement into fresh extraction socket in the first maxillary molar sites: a 3-year prospective study. Implant Dent. 2010; 19: 220-228.
58. Bruschi GB, Crespi R, Cappare P, Bravi F, Bruschi E, Gherlone E. Localized management of sinus floor technique for implant placement in fresh molar sockets. Clin Implant Dent Relat Res. 2013; 15: 243-250.

59. Fugazzotto PA. Implant placement at the time of maxillary molar extraction treatment protocols and report of results. J Periodontol. 2008; 79: 216-223.

60. Summers RB. The osteotome technique: Part 3--Less invasive methods of elevating the sinus floor. Compendium. 1994; 15: 698, 700, 702-704.

61. Ahn SH, Park EJ, Kim ES. Reamer-mediated transalveolar sinus floor elevation without osteotome and simultaneous implant placement in the maxillary molar area: clinical outcomes of 391 implants in 380 patients. Clin Oral Implants Res. 2012; 23: 866-872.

62. Kim JM, Sohn DS, Heo JU, Jun-Sub P, Heui- Seung J, Jee-Won M, et al. Minimally invasive sinus augmentation using ultrasonic piezoelectric vibration and hydraulic pressure: a multicenter retrospective study. Implant Dent. 2012; $21: 536-542$

63. Mazor Z, Horowitz RA, Del Corso M, Prasad HS, Rohrer MD, Dohan Ehrenfest DM. Sinus floor augmentation with simultaneous implant placement using Choukroun's platelet-rich fibrin as the sole grafting material: a radiologic and histologic study at 6 months. J Periodontol. 2009; 80: 2056-2064.

64. Fugazzotto PA. Immediate implant placement following a modified trephine/ osteotome approach: success rates of 116 implants to 4 years in function. Int J Oral Maxillofac Implants. 2002; 17: 113-120.

65. Atieh MA, Alsabeeha NH, Duncan WJ, de Silva RK, Cullinan MP, Schwass $\mathrm{D}$, et al. Immediate single implant restorations in mandibular molar extraction sockets: a controlled clinical trial. Clin Oral Implants Res. 2013; 24: 484-496.

66. O'Sullivan D, Sennerby L, Meredith N. Influence of implant taper on the primary and secondary stability of osseointegrated titanium implants. Clin Oral Implants Res. 2004; 15: 474-480.

67. Atieh MA, Shahmiri RA. Evaluation of optimal taper of immediately loaded wide-diameter implants: a finite element analysis. J Oral Implantol. 2013; 39: 123-132.

68. Ormianer Z, Palti A, Demiralp B, Heller G, Lewinstein I, Khayat PG. Implantsupported first molar restorations: correlation of finite element analysis with clinical outcomes. Int J Oral Maxillofac Implants. 2012; 27: e1-12.

69. Ting M, Palermo M, Donatelli DP, Gaughan JP, Suzuki JB, Jefferies SR. A meta-analysis on the effect of implant characteristics on the survival of the wide-diameter implant. Int J Implant Dent. 2015; 1: 28.

70. Covani U, Cornelini R, Calvo JL, Tonelli P, Barone A. Bone remodeling around implants placed in fresh extraction sockets. Int J Periodontics Restorative Dent. 2010; 30: 601-607.

71. Coelho PG, Jimbo R. Osseointegration of metallic devices: current trends based on implant hardware design. Arch Biochem Biophys. 2014; 561: 99 108.

72. Norton MR. The influence of insertion torque on the survival of immediately placed and restored single-tooth implants. Int J Oral Maxillofac Implants. 2011; 26: 1333-1343.

73. Rodrigo D, Aracil L, Martin C, Sanz M. Diagnosis of implant stability and its impact on implant survival: a prospective case series study. Clin Ora Implants Res. 2010; 21: 255-261.
Austin J Dent - Volume 4 Issue 4 - 2017

ISSN : 2381-9189| www.austinpublishing group.com

Deporter et al. @ All rights are reserved
Citation: Ketabi M and Deporter D. Guidelines for Optimizing Outcomes with Immediate Molar Implant Placement. Austin J Dent. 2017: 4(4): 1079. 